\title{
Quantitative Angiographic Assessment of Elastic Recoil After Percutaneous Transluminal Coronary Angioplasty
}

\author{
Benno J. Rensing, MD, Walter R.M. Hermans, MD, Kevin J. Beatt, MD, Gert Jan Laarman, MD, \\ Harry Suryapranata, MD, Marcel van den Brand, MD, Pim J. de Feyter, MD, \\ and Patrick W. Serruys, MD, PhD
}

\begin{abstract}
Little is known about the elastic behavior of the coronary vessel wall directly after percutaneous transluminal coronary angioplasty (PTCA). Minima! luminal cross-sectional areas of 151 successfully dilated lesions were studied in 136 patients during balloon inflation and directly after withdrawal of the balloon. To circumvent geometric assumptions about the shape of the stenosis after PTCA, a videodensitometric analysis technique was used for the assessment of vascular cross-sectional areas. Elastic recoil was defined as the difference between balloon cross-sectional area of the largest balloon used at the highest pressure and minimal luminal cross-sectional area after PTCA. Mean balloon cross-sectional area was $5.2 \pm 1.6 \mathrm{~mm}^{2}$ with a mean minimal cross-sectional area of $2.8 \pm 1.4$ $\mathrm{mm}^{2}$ immediately after inflation. Oversizing of the balloon (balloon artery ratio $>1$ ) led to more recoil $(0.8 \pm 0.3$ vs $0.6 \pm 0.3 \mathrm{~mm}, p<0.001)$, suggestive of an elastic phenomenon. A difference in recoil of the $\mathbf{3}$ main coronary branches was observed: left anterior descending artery $2.7 \pm 1.3 \mathrm{~mm}^{2}$, circumflex artery $2.3 \pm 1.2 \mathrm{~mm}^{2}$ and right coronary artery $1.9 \pm 1.5 \mathrm{~mm}^{2}(p<0.025)$. The difference was still statistically significant if adjusted for reference area. Thus, nearly $\mathbf{5 0} \%$ of the theoretically achievable cross-sectional area (i.e., balloon cross-sectional area) Is lost shortly after balloon deflation.
\end{abstract}

(Am \Cardiol 1990;66:1039-1044)

From the Catheterization Laboratory, Thoraxcenter, Erasmus Univer sity, Rotterdam, The Netherlands. Manuscript received January 4 , 1990; revised manuscript received and accepted June 18, 1990.

Address for reprints: Patrick W. Serruys, MD, PhD, Catheterization Laboratory, Thoraxcenter, Erasmus University, PO Box 1738 , 3000 DR Rotterdam, The Netherlands.
$\mathrm{P}$ ercutaneous transluminal coronary angioplasty (PTCA) is increasingly being used as an alternative to coronary artery bypass grafting in patients with acute and chronically obstructed vessels. ${ }^{1,2}$ Despite many publications on the mechanism of this treatment modality, little is known about the elastic behavior of the vessel wall during and immediately after angioplasty. Castaneda-Zuniga et $\mathrm{al}^{3}$ proposed an arterial paralysis model in which overstretching of the vessel wall beyond its limits of elasticity was associated with histopathologic features of smooth muscle cell lysis. According to Sanborn et $\mathrm{al},{ }^{4}$ part of the angioplasty mechanism consists of stretching the vessel wall resulting in a fusiform dilatation or localized aneurysm formation. It is, however, a common clinical observation that in some lesions even the application of an oversized balloon leads to a poor angiographic result without a visible intimal tear or dissection. This phenomenon may be attributed to elastic recoil of the vessel wall after balloon angioplasty. Densitometrically assessed cross-sectional areas are independent of geometric assumptions on the shape of the stenosis and should theoretically be more reliable than geometrically derived cross-sectional areas, especially after the disruptive action of balloon angioplasty which is known to cause asymmetric enlargement of the lumen. ${ }^{5}$ This study was undertaken to determine the contribution of elastic recoil to the immediate result of an angioplasty procedure, with the use of densitometric and contour detection analysis techniques.

\section{METHODS}

Contour detection: The quantitative analysis of the stenotic coronary segments was performed with the computer-assisted Cardiovascular Angiography Analysis System (CAAS), which has been described in detail clsewhere. ${ }^{6.7}$ To analyze a coronary arterial segment a $35-\mathrm{mm}$ cine frame was selected. Electronically, a region of interest $(512 \times 512$ pixels) encompassing the arterial segment to be analyzed was digitized with a high-fidelity videocamera. Contours of the arterial segments were detected automatically on the basis of the weighted sum of first and second derivative functions applied to the digitized brightness profile. From these contours the vessel diameter functions are determined by computing the shortest distance between the left and right contour positions (the upper curve in Figure 1). Conversion of the diameter measurements of the vessels to absolute values was achieved by using the contrast catheter as a 
scaling device. To this end the contours of a user-defined portion of the optimally magnified catheter (optimal magnification factor $2 \sqrt{2}$ ) are detected automatically and corrected for pincushion distortion caused by the image intensifiers. In arteries with a focal obstructive lesion and a clearly normal proximal or distal arterial segment, the choice of the reference region is straightforward and simple. However, in cases where the proximal or distal part of the arterial segment shows combinations of stenotic and ectatic areas, the choice may become difficult. To circumvent these problems, we implemented a method that is independent on a user defined reference region. This technique is denoted "interpolated reference diameter measurement." 8 The principle of this technique is the computer estimation of the original vessel diameter at the site of obstruction (Figure 1). The white areas in the figure are measures for the "atherosclerotic plaque" and are defined by the actual luminal contours and the reconstructed reference contours. The length of the obstruction site is determined from the diameter function on the basis of curvature analysis and expressed in millimeters. Using the reconstructed borders of the vessel wall, the computer can calculate a symmetry coefficient for the stenosis: a symmetrical lesion having a value of 1 and a severe ec-
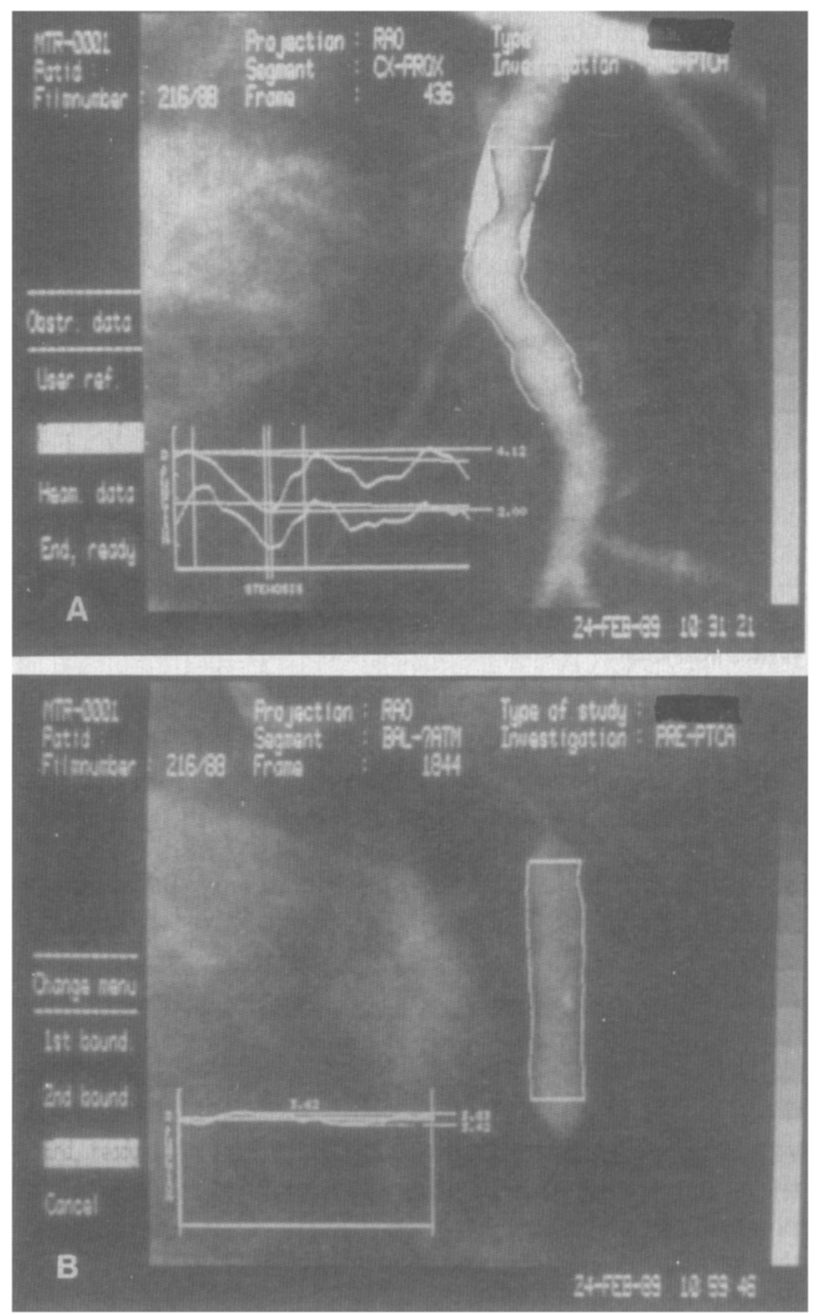

centric lesion having a value of 0 . Symmetry is defined as the coefficient of the left hand distance between the reconstructed and actual vessel contours and the right hand distance between reconstructed and actual contours at the site of obstruction. In this equation the largest distance between actual and reconstructed contours becomes the denominator. The curvature value at the obstruction site, as a measure for coronary bending, is computed as the average value of all the individual curvature values along the centerline of the coronary segment, with the curvature defined as the first derivative of the tangent as it moves along the centerline, which for a circle is equal to the reciprocal of the radius.

Densitometric procedure: Constitution of the relation between path length of the x-rays through the artery and the brightness value requires a detailed analysis of the complete $x$-ray/cine/video chain, including the film development process. ${ }^{9}$ For the first part of the chain from the $x$-ray source to the output of the image intensifier, Lambert Beer's law is assumed to be valid for the $\mathrm{x}$-ray absorption and certain models for the $\mathrm{x}$ ray source and the image intensifier are applied. Sensitometric transfer functions were assessed from 21 calibrated density frames, which are processed photographically simultaneously with the coronary cine film. These 21 density frames are then exposed homogenously with a specially developed sensitometer having the same color temperature as the output screen of the image intensifier.

The contours of a selected arterial segment are detected as previously described. On each scanline perpen-

FIGURE 1. Single frame angiograms of a proximal, circumflex artery (CX-PROX). Contours and densitometric analysis of the severity of the obstruction (Obstr.). The white areas are a measure for the "atherosclerotic" plaque and are defined by the difference between the actual luminal contours and the "interpolated" reference contours. Superimposed on the videoimage are the diameter function curves (upper curve) and the densitometric area function curve (lower curve) together with the "interpolated reference" curves. A, predilatation (before percutaneous transluminal coronary angioplasty [PRE-PTCA] minimal luminal cross-sectional area is $\mathbf{3 . 5}$ $\mathrm{mm}^{2}, B, 3.5 \mathrm{~mm}$ balloom, filmed at highest inflation pressure; C, after dilatation (POST-PTCA), minimal luminal cross-sectional area is $6.0 \mathrm{~mm}^{2}$.

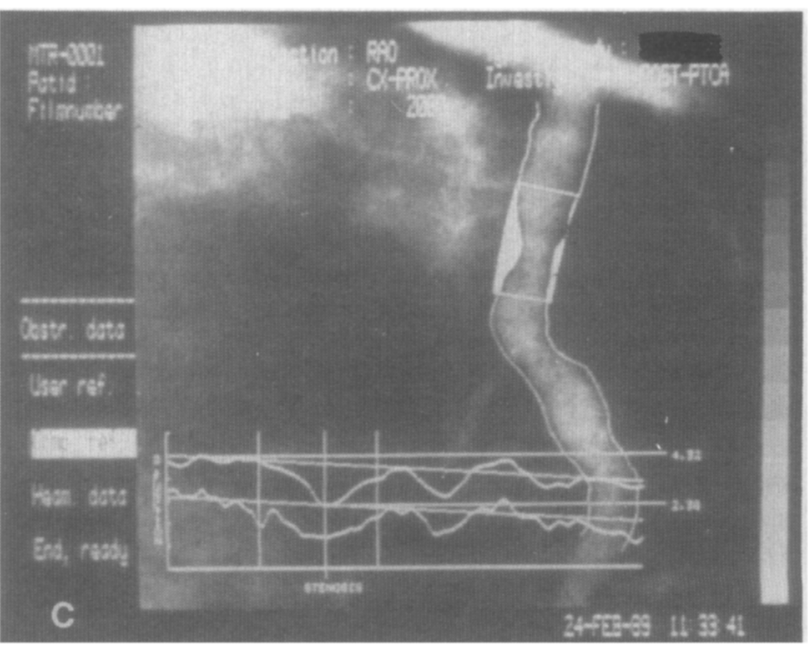


dicular to the centerline a profile of brightness values is measured. This profile is transformed into an absorption profile by means of the computed transfer functions. The background contribution is estimated by an interpolative method and subtraction of this background yields the net cross-sectional absorption profile. Integration of this function results in a measure for the crosssectional area at the particular scanline. By repeating this procedure for each scanline, the cross-sectional area function is obtained. The severity of the obstruction can thus be expressed in $\mathrm{mm}^{2}$, by comparing the minimal area value at the obstruction with the reference value obtained after an interpolative approach, which is similar to that described earlier for diameter measurements.

Validation of this densitometric analysis technique was done by analyzing cine films of perspex models filled with a contrast agent and filmed at $4 \mathrm{kV}$ levels. Accuracy was found to be $2.8 \%$ and precision $1.8 \% .10$ The densitometrically determined area stenosis, as found by other investigators, correlates well with percentage reduction of cross-sectional area measured histologically in postmortem hearts. 11,12

Assessment of elastic recoil: One hundred fifty-one successfully dilated segments of 136 patients were analyzed. A successful PTCA was defined as a visually assessed diameter stenosis after PTCA of $<50 \%$. Single identical views before and after PTCA, and during complete expansion of the largest balloon at highest inflation pressure were chosen for densitometric analysis. Both polyvinyl chloride and polyethylene balloons were used for dilatation depending on the choice of the operator. Inflation pressure and duration of inflation were left to the discretion of the operator. Mean balloon crosssectional areas were calculated from diameter values, assuming a circular cross section at maximal inflation pressure. The same $\mathrm{x}$-ray setting in terms of kilovoltage and milliamperes was used during the 3 cine recordings. To have the segment to be analyzed as perpendicular to the incoming $\mathrm{x}$-rays as possible, a view was chosen with the coronary artery appearing least foreshortened. The same amount of nitrates, either nitroglycerin, 0.1 to 0.3 $\mathrm{mg}$, or isosorbide dinitrate, 1 to $3 \mathrm{mg}$, was given intracoronarily before the pre- and postangioplasty cine recordings. This was done to dilate the vessel maximally and thus to control the varying influence of vasomotor tone on luminal dimensions. Elastic recoil was then calculated as the difference between the minimal luminal cross-sectional area after PTCA and the mean balloon cross-sectional area $\left(\mathrm{mm}^{2}\right)$. A representative analysis, with the detected contours, the diameter function curve and the densitometric area function curve superimposed on the original video image, is shown in Figure 1 for a circumflex lesion.

\section{RESULTS}

At quantitative analysis $140(92 \%)$ of the dilatations were successful using a $<50 \%$ diameter stenosis after PTCA as the success criterion. If in addition a $>20 \%$ improvement in diameter stenosis was required for a successful dilatation, $110(72 \%)$ lesions were successfully dilated using quantitative measurements. The densi-

\begin{tabular}{|llll|}
\hline TABLE I Recoil in 151 & Coronary & Arterial Narrowings \\
\hline & Before PTCA & After PTCA & p Value \\
\hline Reference area $\left(\mathrm{mm}^{2}\right)$ & $6.0 \pm 2.5$ & $6.2 \pm 2.5$ & NS \\
MLCA $\left(\mathrm{mm}^{2}\right)$ & $1.1 \pm 0.9$ & $2.8 \pm 1.4$ & $\mathrm{p}<0.001$ \\
Balloon-CSA $\left(\mathrm{mm}^{2}\right)$ & & $5.2 \pm 1.6$ & \\
Recoil $\left(\mathrm{mm}^{2}\right)$ & & $2.4 \pm 1.4$ & $\mathrm{p}<0.001$ \\
\hline CSA = cross-sectional area; MLCA = minimal luminal cross-sectional area; NS $=$ \\
difference not significant: PTCA = nercutaneous transluminal coronary angioplasty; \\
Recoil = balloon CSA-MLCA after PTCA. \\
\hline
\end{tabular}

\begin{tabular}{|llll|}
\hline $\begin{array}{l}\text { TABLE II Effect of Balloon Oversizing on the Amount of } \\
\text { Elastic Recoil }\end{array}$ & & & \\
\hline Balloon-Artery Ratio & $\leq 1$ & $>1$ & $p$ Value \\
\hline No. of lesions & 87 & 64 & \\
Reference-diameter $(\mathrm{mm})$ & $3.0 \pm 0.5$ & $2.3 \pm 0.4$ & $p<0.001$ \\
Balloon-diameter $(\mathrm{mm})$ & $2.5 \pm 0.4$ & $2.6 \pm 0.4$ & NS \\
Recoil (mm) & $0.6 \pm 0.30$ & $0.8 \pm 0.3$ & $\mathrm{p}<0.001$ \\
\hline Balloon-artery ratio = balloon diameter/reference diameter; NS $=$ difference not \\
significant.
\end{tabular}

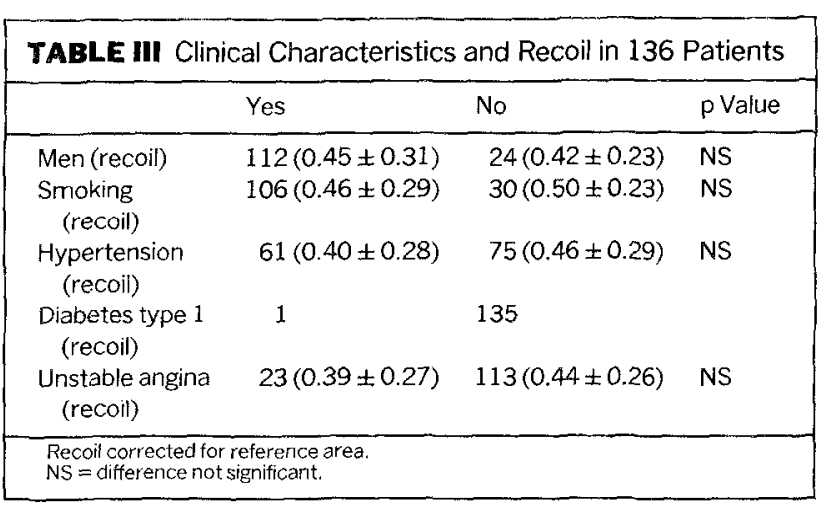

tometric analysis of the 151 segments is listcd in Tablc I. Mean age of the 136 patients was $56.8 \pm 8$ years. There was no significant change in "interpolated" reference area after PTCA: Before PTCA $6.0 \pm 2.5 \mathrm{~mm}^{2}$, after PTCA $6.2 \pm 2.5 \mathrm{~mm}^{2}$ (difference not significant). The minimal luminal cross-sectional area increased from $1.1 \pm 0.9$ to $2.8 \pm 1.4 \mathrm{~mm}^{2}(\mathrm{p}<0.001)$. The mean balloon cross-sectional area was $5.2 \pm 1.6 \mathrm{~mm}^{2}$. Elastic recoil was $2.4 \pm 1.4 \mathrm{~mm}^{2}$. Thus, nearly $50 \%$ of the theoretically achievable cross section (i.e., balloon cross-sectional area) was lost immediately after the last balloon deflation. A subset of 16 patients (18 lesions) were angiographically reexamined 24 hours after PTCA as part of a study looking at changes in coronary flow reserve in the first 24 hours after balloon dilatation. Minimal luminal cross-sectional area directly after PTCA in this group was $2.0 \pm 0.8 \mathrm{~mm}^{2}$ and $1.9 \pm 0.5$ at 24 hours (difference not significant).

Balloon oversizing and elastic recoil: For each stenotic lesion the balloon-artery ratio was calculated. A ratio $>1$ indicates oversizing of the balloon. The mean balloon-artery ratio in this study was $0.95 \pm 0.18$. This indicates a conservative balloon handling, considered to give optimal dilatation of the stenotic lesion with minimal residual stenosis and the smallest incidence of coro- 


\begin{tabular}{|lllll|}
\hline \multicolumn{2}{|l|}{ TABLE IV Angiographic and Procedural Characteristics and Recoil of 151 Lesions } & & \\
\hline & Yes & No & p Value & Mean \\
\hline Lesion length $>5.2 \mathrm{~mm}$ and $<7 \mathrm{~mm}$ (recoil) & $50(0.48 \pm 0.25)$ & $101(0.43 \pm 0.33)$ & NS & $6.4 \pm 2.4 \mathrm{~mm}$ \\
Calcified lesion (recoil) & $22(0.43 \pm 0.29)$ & $129(0.45 \pm 0.45)$ & NS & \\
Symmetry $<0.37$ (recoil) & $51(0.48 \pm 0.33)$ & $100(0.41 \pm 0.30)$ & $p=0.07$ & $0.5 \pm 0.3$ \\
Plaque area $<4.5 \mathrm{~mm}^{2}$ (recoil) & $50(0.53 \pm 0.33)$ & $101(0.41 \pm 0.27)$ & $p<0.01$ & $6.8 \pm 3.9 \mathrm{~mm}^{2}$ \\
Curvature $<12.5$ units (recoil) & $51(0.53 \pm 0.34)$ & $100(0.43 \pm 0.31)$ & $p<0.01$ & $17.7 \pm 10.4$ \\
Max. infl. pres. $<8$ atm (recoil) & $49(0.46 \pm 0.24)$ & $102(0.46 \pm 0.35)$ & NS & $9.6 \pm 2.5 \mathrm{~atm}$ \\
Inflation duration $<220$ seconds (recoil) & $50(0.47 \pm 0.30)$ & $101(0.44 \pm 0.29)$ & NS & $309 \pm 170$ seconds \\
\hline Recoil corrected for reference area. See text for description of cutoff points. & & & \\
Max. infl. pres. = maximal inflation pressure of the balloon: NS = difference not significant. & & & \\
\hline
\end{tabular}

TABLE $\mathbf{V}$ Recoil in the Three Main Coronary Arteries

\begin{tabular}{|lllll|}
\hline & $\begin{array}{l}\text { LAD } \\
(n=77)\end{array}$ & $\begin{array}{l}\text { LC } \\
(n=34)\end{array}$ & $\begin{array}{l}\text { Right } \\
(n=40)\end{array}$ & ANOVA \\
\hline Balloon CSA $\left(\mathrm{mm}^{2}\right)$ & $5.2 \pm 1.7$ & $5.5 \pm 1.5$ & $4.9 \pm 1.4$ & $\mathrm{NS}$ \\
MLCA after PTCA $\left(\mathrm{mm}^{2}\right)$ & $2.5 \pm 1.3$ & $3.1 \pm 1.2$ & $3.0 \pm 1.7$ & $\mathrm{NS}$ \\
Recoil $\left(\mathrm{mm}^{2}\right)$ & $2.7 \pm 1.3$ & $2.3 \pm 1.2$ & $1.9 \pm 1.5$ & $p<0.025$ \\
Recoil $/$ rcference area & $0.5 \pm 0.3$ & $0.4 \pm 0.2$ & $0.3 \pm 0.3$ & $\mathrm{p}<0.05$ \\
\hline $\begin{array}{l}\text { ANOVA = analysis of variance; CSA }=\text { cross-sectional area; } \text { LAD }=\text { left anterior } \\
\text { descending artery; LC = left circumflex artery; MLCA } \\
\text { sectional area: NS = difference not significant. }\end{array}$ & & & \\
\hline
\end{tabular}

nary dissection. ${ }^{13,14}$ Lesions with a ratio $>1$ (oversizing) were compared with lesions with a ratio $\leq 1$. The comparative data are listed in Table 1I. No difference was found in balloon diameter between the groups. As expected, reference diameter was higher in the group with a ratio $\leq 1$. Elastic recoil was more pronounced in the second group $(0.84 \pm 0.29$ vs $0.64 \pm 0.30 \mathrm{~mm}$, p $<0.001)$. Thus, oversizing of the balloon leads to more elastic recoil. These results agree with elastic phenomena: more stretch leads to more recoil (within limits of elasticity).

Clinical characteristics and recoils Clinical characteristics and risk factors of the 136 patients are listed in
Table III. No differences in elastic recoil were observed for gender, the presence or absence of risk factors and the presence or absence of unstable angina.

Quantitative angiographic lesion characteristics and recoil: Quantitative data on lesion morphology before angioplasty are listed in Table IV. To avoid arbitrary subdivision of data, cutoff criteria for lesion length, symmetry, plaque area and curvature value were derived by dividing the data in 3 groups so that each group contained about one-third of the population. The group with the highest amount of recoil was then compared with the 2 other groups. Lesions with a small plaque area and lesions with a shallow curvature showed significantly more recoil (Table IV).

Procedural related variables and recoil: Table IV lists the total inflation duration and maximal balloon inflation pressure in relation to clastic recoil. No differences in elastic recoil were observed.

Recoil in the three main coronary arteries: The amount of recoil was calculated in the left anterior descending artery $(n=77)$, the circumflex artery $(n=$ $34)$ and in the right coronary artery $(n=40)$. Data are listed in Table $\mathrm{V}$. The amount of recoil was significantly larger in the left anterior descending artery compared with the circumflex and right coronary arteries, 2.7, 2.3

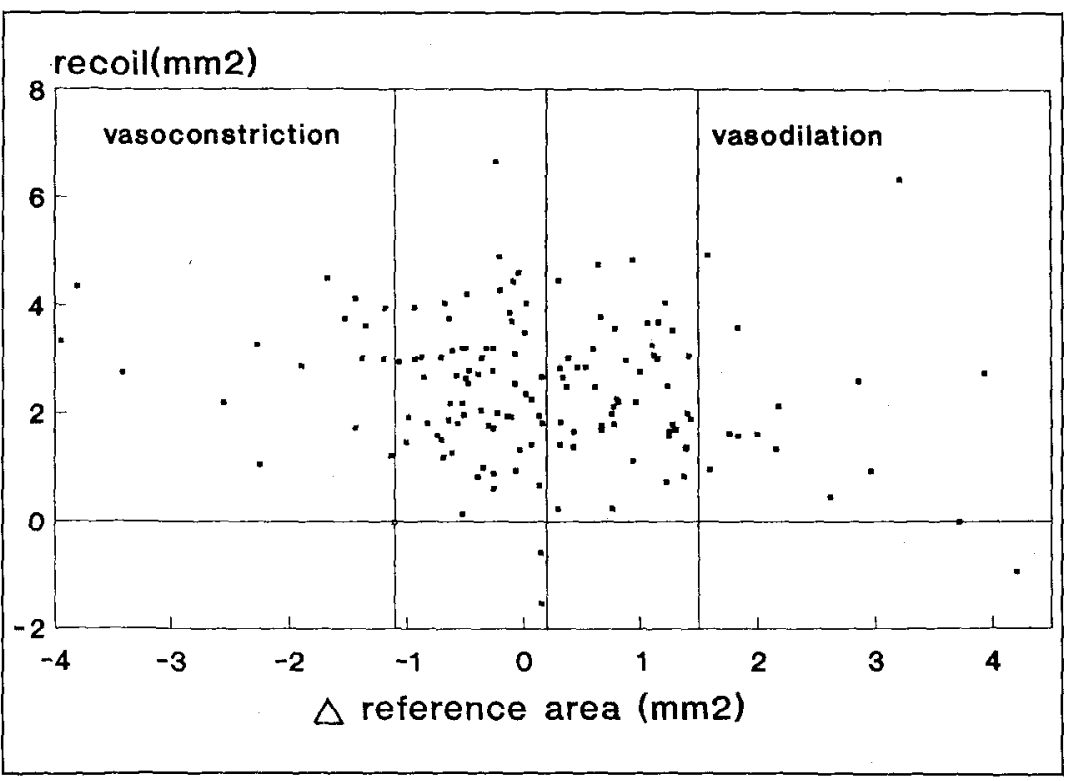

FIGURE 2. In this scatterplot the difference in interpolated reference area before and after percutaneous transluminal coronary angioplasty is plotted against the amount of recoil for each segment. The mean difference in reference area was 0.2 $\pm 1.3 \mathrm{~mm}^{2}$ (vertical lines in graph). The values are randomly distributed around the mean value of $0.2 \mathrm{~mm}^{2}$, suggesting that spasm was effectively eliminated. 
and $1.9 \mathrm{~mm}^{2}$, respectively $(p<0.025)$. When normalized for reference area the difference was still statistically significant.

\section{DISCUSSION}

Vasoconstriction at the dilatation site is a common cause of early luminal narrowing. As has been shown elegantly by Fischell et al ${ }^{15}$ this can be rapidly reversed by an intracoronary injection of nitrates. Because we gave intracoronary nitrates before the pre- and postPTCA cine runs, it seems unlikely that the amount of recoil observed was caused by vasomotion. In Figure 2 the difference between the reference area before and after PTCA is plotted against the amount of recoil for each site. The values are randomly distributed around the mean value of $0.2 \mathrm{~mm}^{2}$, suggesting the absence of vasoconstriction at the post-PTCA film.

Platelet deposition, and the formation of a nonocclusive mural thrombus despite full heparinization, is not an uncommon finding in postmortem hearts obtained from patients who die in the first hours after angioplasty. ${ }^{16}$ This has also been confirmed by angioscopy 15 to 30 minutes after PTCA. ${ }^{17}$ However, our post-PTCA angiograms were recorded within minutes of the last dilatation. Although we cannot rule out the possibility that mural thrombus formation is partly responsible for the observed phenomenon, we believe it cannot explain the $50 \%$ decrease in luminal area found. Subintimal hemorrhage is also a cause of severe early luminal narrowing or acute closure, a process which is usually impossible to reverse and nearly always results in a failed PTCA. In this study only successfully dilated lesions were analyzed.

The mean balloon cross-sectional area was derived over the total length of the balloon and compared with the minimal luminal cross-sectional area measured immediately after PTCA. In this study, recoil of the part of the dilated segment adjacent to this area was not specifically studied. We assumed a uniform expansion of the balloon at maximal inflation pressure. Theoretically, recoil should be assessed using the minimal luminal balloon cross-sectional area.

The 18 lesions restudied 24 hours after PTCA showed no difference in minimal luminal cross-sectional area with respect to the cross-sectional area directly after PTCA. This suggests that elastic recoil is an instantaneous phenomenon. This finding does not agree with the findings of Nobuyoshi et al, ${ }^{18}$ who found a significant deterioration of minimal luminal diameter 1 day after PTCA. However, the small size of this subgroup may not be representative of the total population. A trend toward more recoil was observed in asymmetric lesions. In these lesions the balloon will preferrably stretch the nondiseased part of the vessel circumference with a subsequent larger elastic recoil. ${ }^{19}$ The fact that a small plaque area and a low curvature value are attended with a significant higher amount of elastic recoil may be due to the fact that dissections have been found most often in areas containing thick atherosclerotic plaques and lesions with a high bending. ${ }^{20,21}$ Gross disruption of the vessel wall may prevent the recoil phenomenon. Procedural variables had no influence on the amount of recoil. Longer inflations and higher inflation pressures are often used after an initially poor angioplasty result. Only a randomized trial can indicate to what extend procedural factors influence proccdural outcome.

Jain et $\mathrm{al}^{22}$ found, using an in vivo technique for obtaining balloon pressure-volume loops, a pattern consistent with stretching of the arterial wall in $56 \%$ of lesions. A pressure-volume loop consistent with stretching of the vessel was a far more common event than a cracking pattern $(17 \%)$. Stretching within limits of elasticity implies its counterpart elastic recoil. More stretching should lead to more recoil. In our series, oversizing of the balloon (i.e., a balloon-artery ratio $>1$ ) was associated with more recoil, indicative of the elastic phenomenon. Dobrin described pressure radius curves of potassium cyanide-poisoned carotid arteries of mongrel dogs. At low pressures, the vessel exhibited large changes in radius with each step in pressure, whereas at high pressure it showed very slight changes in radius. The curve described an elastic hysteresis loop, with the ascending and descending limb close to each other at all pressures, suggesting no active muscle contraction involvement in the retraction process. ${ }^{23}$

The differences in elastic recoil observed in the 3 coronary arteries cannot be easily be explained. Differences in histologic structure or differences in plaque composition in the coronary arteries might be an explanation. To our knowledge these differences have not been reported.

\section{REFERENCES}

1. Dorros $G$, Lewin RF, Janke L. Multiple lesion transluminal coronary angioplasty in single and multivessel coronary artery disease: acute outcome and longterm effect. I Am Coll Cardiol 1987;10:1007-1013.

2. Feyter PJ de, Serruys PW, Brand M van den, Balakumaran K, Mochtar B, Soward AL., Arnold AER, Hugenholtz PG. Emergency coronary angioplasty in refractory unstable angina. $N$ Engl I Med 1985;313:342-346.

3. Castaneda-Zuniga WR, Formanek A, Tadavarthy M, Vlodaver Z, Edwards $\mathrm{JE}$, Zollikofer C, Amplatz K. The mechanism of balloon angioplasty, Radiology 1980;135:565-571.

4. Sanborn TA, Faxon DP, Haudenschild CG, Gottsman SB, Ryan TJ. The mechanism of transluminal angioplasty: evidence for aneurysm formation in experimental atheroscicrosis. Circulation 1983;68:1136-1140.

5. Serruys PW, Reiber JHC, Wijns W, Brand van den M, Kooyman CI, Katen ten HJ, Hugenholtz PG. Assessment of percutaneous transluminal coronary angioplasty by quantitative coronary angiography: diameter versus densitometric area measurements. Am $J$ Cardiol 1984:54:482-488.

6. Reiber JHC, Kooyman CJ, Slager CJ. Coronary artery dimensions from cineangiograms; methodology and validation of a computer assisted analysis procedure. IEEE Trans Med Imaging 1984;3:131-141.

7. Reiber JHC, Serruys PW, Kooyman CJ, Wijns W, Slager CJ, Gerbrands JJ, Schuurbiers JCH, den Boer A, Hugenholtz PG. Assessment of short-, medium-, and long-term variations in arterial dimensions from computer-assisted quantitation of coronary cineangiograms. Circulation 1985;71:280-288.

8. Kooyman CJ, Reiber JHC, Gerbrands JJ, Schuurbiers JCH, Slager CJ, den Bocr A, Serruys PW. Computer-aided quantitation of the severity of coronary obstructions from single view cineangiograms. International Symposium on Medical lmaging and Image Intcrpretation. IEEE catalog no. 82 CH 1804-4, 1982.5964.

9. Reiber JHC, Slager CJ, Schuurbiers JCH, den Boer A, Gerbrands JJ, Troost GJ, Scholts B, Kooyman CJ, Serruys PW. Transfer functions of the $x$-ray cine viden chain applied to digital processing of coronary cineangiograms. In: Heintzen $\mathrm{PH}$, Brennecke R, eds. Digital Imaging in Cardiovascular Radiology. StuttgartNew York: George Thieme Verlag, 1983:89-104.

10. Reiber JHC, Kooijman CJ, Slager C. Improved densitometric assessment \% area stenosis from coronary cineangiograms (abstr). Xth World Congress Cardiol 
$1986 ; 216$.

11. Janssen $\mathbf{J}$, Brugada $P$, Wellens $H J J$. A critical evaluation of quantitative coronary angiography. In Janssen J, ed. Clinical Application of Videoimage Processing in Cardiac Angiology. Assen, The Netherlands: van Gorcum, 1989 104-122.

12. Nichols AB, Gabrich $C$, Ferioglio J, Esser $P$. Quantification of relative coronary stenosis by cinevideodensitometric analysis of coronary cineangiograms Circulation 1984;69:512-522.

13. Roubin GS, Douglas JS Jr, King III SB, Lin S, Hutchinson N, Thomas RG Grünzig AG. Influence of balloon size on initial success, acute complications, and restenosis after percutaneous transluminal coronary angioplasty. A prospective randomized study. Circulation 1988;78:557-565.

14. Nichols AB, Smith R, Berke AD, Shlofmitz RA, Powers ER. Importance of balloon size in coronary angioplasty. J Am Coll Cardiol 1988;13;1094-1100. 15. Fischell TA, Derby G, Tse TM, Stadius ML. Coronary artery vasoconstriction routinely occurs after percutaneous transluminal coronary angioplasty. A quantitative arteriographic analysis. Circulation 1988;78:1323 1334.

16. Waller BF, Gorfinkel HJ, Rogers FJ, Kent KM, Roberts WC. Larly and late morphologic changes in major epicardial coronary arteries after percutaneous transluminal coronary angioplasty. Am J Cardiol 1984;53:42C-47C.
17. Uchida $Y$, Hasegawa K, Kawamura K, Shibuya I. Angioscopic observation of the coronary luminal changes induced by percutaneous transluminal coronary angioplasty. Am Heart $J$ 1989;117:769-776.

18. Nobuyoshi $M$, Kimura $T$, Nosaka $H$. Restenosis after succesful percutaneous transluminal coronary angioplasty: serial angiographic follow-up of 299 patients. $J$ Am Coll Cardiol 1988;12:616-623.

19. Waller BF. "Crackers, breakers, stretchers, drillers, scrapers, shavers, burners, welders and melters." The future treatment of coronary artery discase? A clinical-morphologic assessment. $J$ Am Coll Cardiol 1989;13:969-987.

20. Zollikofer C, Chain J, Salomonowitz E, Runge W, Bruehlman W, Castaneda-Zuniga W, Amplatz K. Percutaneous transluminal angioplasty of the aorta. Radiology 1984;151:355-363.

21. Ellis SG, Roubin GS, King III SB, Weintraub JS, Thomas RG, Cox WR. Angiographic and clinical predictors of acute closure after native vessel coronary angioplasty. Circulation 1988;77:372-379

22. Jain A, Demer LL, Raizner AE, Hartley CJ, Lewis JM, Roberts $R$. In vivo assessment of vascular dilatation during percutaneous transluminal coronary angioplasty. Am J Cardiol 1987;988-992.

23. Dobrin PB, Rovick A. Influence of vascular smooth muscle on contractile mechanics and elasticity of arteries. Am J Physiol 1969;217:1644-1651. 